\title{
Community based integrated vector management for malaria control: lessons from three years' experience (2016-2018) in Botor-Tolay district, southwestern Ethiopia
}

\author{
Abebe Asale ${ }^{1 *}$ (D), Dereje Kussa ${ }^{1}$, Melaku Girma², Charles Mbogo ${ }^{3,4}$ and Clifford Maina Mutero ${ }^{4,5}$
}

\begin{abstract}
Background: Integrated vector management (IVM) remains a key strategy in the fight against vector-borne diseases including malaria. However, impacts of the strategy should be regularly monitored based on feedback obtained through research. The objective of this study was to assess the impact of IVM for malaria control in BotorTolay district, southwestern Ethiopia after three years (2016-2018) of IVM implementation.

Method: Prior to the implementation of IVM, a survey of socio-demographic, malaria burden, and communities' perception towards malaria control was conducted in 200 households selected at random from 12 villages using standard questionnaire. Households were revisited after three years of project implementation for impact assessment. Compiled malaria case data was obtained from district health bureau for the three years period of the study while adult mosquito collection was conducted during each year using CDC light traps. Monthly larval mosquito collections were made each year using standard dipping method. Community education and mobilization (CEM) was made through different community-based structures.

Results: The proportion of respondents who sought treatment in health facilities showed a significant increase from $76 \%$ in 2015 to $90 \%$ in $2018(P<0.001)$. An average of 6.3 working and 2.3 school days were lost per year in a household due to parents and children falling sick with malaria. Malaria costs in a household in Botor-Tolay averaged 13.3 and 4.5 USD per episode for medical treatment and transportation respectively. Significantly fewer adult mosquitoes were collected in 2018 (0.37/house/trap-night) as compared to 2015 (0.73/house/trap-night) $(P<.001)$. Malaria cases significantly declined in 2018 (262) when compared to the record in 2015 (1162) $(P<0.001)$. Despite improved human behavioral changes towards mosquito and malaria control, there were many setbacks too. These include reluctance to seek treatment in a timely manner, low user compliance of LLINs and low net repairing habit.

Conclusion: The coordinated implementation of community-based education, environmental management, larviciding together with main core vector control interventions in Botor-Tolay district in Southwestern Ethiopia have contributed to significant decline in malaria cases reported from health facilities. However, commitment to seeking treatment by people with clinical symptoms of malaria and to repair of damaged mosquito nets remained low.
\end{abstract}

Keywords: Integrated vector management, Malaria, Health seeking behavior, Vector control, Ethiopia

\footnotetext{
* Correspondence: abebea663@gmail.com

'International Center of Insect Physiology and Ecology, Addis Ababa,

Ethiopia

Full list of author information is available at the end of the article
}

(c) The Author(s). 2019 Open Access This article is distributed under the terms of the Creative Commons Attribution 4.0 International License (http://creativecommons.org/licenses/by/4.0/), which permits unrestricted use, distribution, and reproduction in any medium, provided you give appropriate credit to the original author(s) and the source, provide a link to the Creative Commons license, and indicate if changes were made. The Creative Commons Public Domain Dedication waiver (http://creativecommons.org/publicdomain/zero/1.0/) applies to the data made available in this article, unless otherwise stated. 


\section{Background}

Vector-mediated diseases continue to be a global health threat accounting for an estimated $17 \%$ of all infectious diseases and more than 700,000 deaths due to diseases such as malaria, yellow fever, human African trypanosomiasis, leishmaniasis, dengue, schistosomiasis, Chagas disease, Japanese encephalitis and onchocerciasis, and putting more than $80 \%$ of the world's population at risk [1]. Malaria impact ranks high among all vector borne diseases with a total of 216 million cases and 445,000 deaths reported in 2016 alone, with Africa accounting for about $90 \%$ of the disease cases and deaths [2].

Vector control constitutes a key element of disease containment and the agenda for malaria elimination as envisaged by national governments together with important stakeholders including World Health Organization, Roll Back Malaria and many other non-governmental organizations [3]. Calls to reverse malaria morbidity and mortality have been ongoing during the last three decades, especially focused on the use of long-lasting insecticidetreated nets (LLINs) and indoor residual spraying as the primary vector control tools [4]. However, following apparent stagnation of malaria reduction among different countries due to technical and other challenges, interest has increasingly shifted to the use of an integrated vector management approach aimed at, among other things, slowing down the emergence and spread of vector resistance to most public health insecticides.

Integrated vector management is a participatory approach which encourages the involvement of different stakeholders to optimize the use of resources potentially available for vector control [5, 6]. Pertinent questions defining IVM include: how can we achieve higher intervention coverage and intended protection target with less money? How can the public health sector work together with other stakeholders, for instance, agriculture and urban planning sectors that directly or indirectly affect national health policies? Which interventions work effectively, when and where? IVM emphasizes on engaging stakeholders and end-users particularly mobilizing community members as part of the intervention itself so that they become central players in disease control and prevention instead of being passive receivers of government "program packages".

Community mobilization and education together with capacity building are necessary elements of IVM which help to bring together local community members, local government bodies, religious and civil society organizations. As an example, community mobilization and education conducted in different countries as part of IVM has proved to be effective in the control of vectors of dengue [7-9] and malaria [10-12].

In Botor-Tolay district despite the high coverage of IRS and scaling up of LLINs, there was no documented information yet on the community's perception as to whether the envisaged control and elimination programs could work effectively. The aim of this study was to assess the impact of continuous community education and mobilization (CCEM) on knowledge, attitude and practice in relation to malaria control and prevention in the context of IVM.

\section{Methods}

\section{Study area and period}

This study was conducted in 12 villages located in Botor-Tolay District, Jimma Zone, Oromia regional state of Southwestern Ethiopia. The study area lies about 243 $\mathrm{km}$ South West of Addis Ababa, the capital city of Ethiopia, approximately $8^{0} 21^{\prime} 53.4^{\prime \prime} \mathrm{N}$ and $37^{\circ} 20^{\prime} 12.6^{\prime \prime} \mathrm{E}$. The study area lies at an altitude ranging between 1100 to $1800 \mathrm{~m}$ above sea level. The mean annual temperature ranges from $19{ }^{\circ} \mathrm{C}$ to $30{ }^{\circ} \mathrm{C}$ and the mean annual rainfall varies from 400 to $1500 \mathrm{~mm} /$ year.

The communities are mainly engaged in mixed agriculture and small-scale trade at village level. Malaria prevalence in the area is $1.65 \%$ (cross sectional prevalence survey conducted by icipe 2015). Out of 31 total "Kebeles" (smallest administration unit of 500 to 700 households in Ethiopia) in Botor-Tolay district 26 of them are malarious (district health office, personal communication). Peak malaria transmission occurs during the period from September to November, like other parts of Ethiopia [13]. The study was conducted in 12 villages, selected based on accessibility and proximity (10-100 M) of mosquito breeding larval habitats in relation to houses.

\section{Study design}

The study was conducted as part of monitoring and evaluation of the implementation of CEM for the prevention and control of malaria over a three-year period from January 2016 to December 2018. The study included the following two main components described in more detail in sections below: (a) implementation of community education and vector control interventions; (b) surveillance and impact assessment through longitudinal monitoring of trends in indoor relative adult mosquito density, mosquito larval populations, malaria case report from local health centers. In addition, two cross-sectional socio-demographic household surveys were conducted to determine community knowledge, attitude and practice, one survey at baseline in 2015/16 and the second at the end of post-intervention period in 2018 .

\section{Interventions}

The interventions used in this study include: (a) Community Education and Mobilization (CEM) to promote malaria IVM; (b), larval source management through 
larviciding with Bacillus thuringiensis israelensis and environmental management, (c) use of long-lasting insecticide treated nets (LLIN's) and indoor residual spraying (IRS). The interventions are described in more detail below:

\section{Community education and mobilization (CEM)}

Despite considered as key component in the policy document of the NMCP, the community education and mobilization intervention were given less emphasis in Ethiopia as stakeholders and program managers focus on IRS and LLINs. Thus, in this study more focus and supervision was given to CEM to integrate it with ongoing mainstay interventions. Reformations were made in order to maximize its efficacy. These include establishment of different community-based structures, many of which had been established and used from as early as 2013 during initiation of IVM activities in Tolay area (Girma et al., unpublished) and schools' anti-malaria clubs. Community based IVM working structures were composed of village administrator, village health extension worker, village agricultural development agent, community elder, youth organizer and community member with their total number ranging from 4 to 5 . These working groups were trained with CEM and larval source management (LSM) first and then entitled to mobilize the community members. Monthly campaign was conducted by these structures in rainy season and subsequent months. As part of environmental management community and student members were involved in filling temporary water bodies, stagnant pools, roadside and farmland ditches and environmental cleaning.

A group of young people with high school diploma were recruited from communities and trained as mosquito scouts by ICIPE for malaria control field coordinating staffs. The trainees in turn trained communitybased malaria control working groups including various community groups and school anti-malarial club member students. ICIPE for malaria control field coordinating staff was responsible for designing, training, implementing and surveillance of both entomological and epidemiological information.

\section{Vector control methods}

Indoor residual spray (IRS) The national malaria control program discontinued intervention of DDT in 2010 due to insecticide resistance and environmental pollution concerns [14]. DDT was first replaced by pyrethroids and following the report of widespread resistance against pyrethroids, the ministry decided in 2012 to adopt mosaic spraying approach in which different classes of insecticides are applied to different areas of the country considering the insecticide resistance information of the area [14]. Eighty-three (83\%), 75 and $69 \%$ of residential structures in the district were sprayed by the Ministry of Health $(\mathrm{MOH})$ as part of National Malaria Control Program (NMCP) in 2016, 2017 and 2018 respectively. The continues decline in IRS coverage was justified by 1) malaria incidence decline in the district documented in recent years 2) sustained IRS logistic constraint and 3) prioritization of more burdened districts surrounding the area. Spraying was conducted each year during the month of August to September by trained spray workers supervised by government health extension workers. Bendiocarb $80 \%$ WP was used at the rate $0.4 \mathrm{~g} / \mathrm{m}^{2}$ before and during the trial period in all villages selected for IRS.

Long-lasting insecticidal nets (LLINs) These were also provided by $\mathrm{MOH}$ as part of national malaria control activities by the NMCP. Bed net coverage of the community was $83 \%$ in 2015 (icipe impact assessment unit report, 20,115). PermaNet 2.0, (Vestergaard Frandsen Group) and DuraNet (Shobikaa Impex pvt Ltd., Karur, Tamil Nadu 639,006, India) were the two brands of LLINs distributed by the NMCP, at the rate of one bed net for two people (personal communication to the district health office) as per WHO recommended universal net coverage.

Larval source management involving larviciding with Bti and environmental management Larviciding with $\mathrm{B} t i$ and environmental management were led by ICIPE. Bacillus thuringiensis israelensis (Bti) granule (VectoBac G; Valent Biosciences Corporation, USA) was applied once every other week in all accessible anopheline mosquito-breeding habitats identified following standard procedure (Valent BioSciences, 2003) [15]. $\mathrm{Up}$ on identification of positive habitats, mosquito scouts trained with Bti larviciding took the measurement of the water body (length, width and depth). Then they determined the volume of water present in the breeding ground. Then Selected larval breeding habitats were treated with 3 granules/hoofprint to $125-500 \mathrm{~g} \mathrm{Bti} /$ hectare every other week. Environmental management (EM) involved the filling or draining of all temporary mosquito breeding habitats such as hoof and footprints and small rain pools. Both EM and larviciding with Bti was stopped during the dry season (December, January, February, March) as malaria in Ethiopia is seasonal and there is no as such relevant breeding habitats. Larviciding then resumed during the months that follow the rainy season (April, May, June, July, August, September, October and November). 
Surveillance and impact assessment Entomological monitoring

Larval mosquito sampling All potential breeding habitats within the villages at the time of monitoring were inspected for larval mosquitoes using a standard dipper $(11.5 \mathrm{~cm}$ diameter and $350 \mathrm{ml}$ capacity) and pipettes following the guideline of WHO (2013) [16]. Samples were identified and categorized into Anopheles or Culex mosquito species using taxonomic key developed by Gillies \& De Meillon, (1968) [17]. The location and elevation of each habitat was recorded using hand held Global Positioning System (Garmin, USA).

Adult mosquito sampling Adult mosquito were sampled once in dry and wet seasons in all the 12 villages using CDC light traps (Model 512: J. W. Hock Co., Atlanta, USA). Ten CDC traps per village placed about 1.5 $\mathrm{m}$ from the floor near sleeping persons and ran from 8 : $00 \mathrm{p} . \mathrm{m}$. in the evening to 06:00 a.m. in the morning. The ten sentinel houses per village were selected using simple random sampling and were required to be within $100 \mathrm{~m}$ far from each other and from mosquito breeding sites. Samples were taken from the same sentinel houses every month and every year.

Species identification The collected mosquitoes were transported to nearby Tolay field icipe-vector biology laboratory, where mosquitoes were sorted by genus, sex and morphologically identified using taxonomic keys [18].

\section{Epidemiological monitoring}

Botor-Tolay district has 12 health posts and three health centers. Each village has one health posts and the three villages (Ketta, Wayu and Boro) has additional health centers each. All the 12 health posts and three health centers submit weekly malaria report to the district health office. Each health post has one to two health extension workers (HEW) trained and equipped with rapid diagnostic technique for malaria control. The HEW tested every febrile case presented to them using RDT kit and treat with Artemether/Lumefantrine (Coartem ${ }^{\circ}$ ) (all P. falciparum and mixed cases) and with chloroquine (all $P$. vivax cases). They refer all complicated cases to the nearby health center for further diagnosis. The three health centers are equipped with microscopy in addition to RDT. As part of the ongoing malaria cases monitoring program the trend of malaria cases was obtained from district health office. One hundred percent (100\%) reporting coverage was ensured in order to get all the cases reported to respective health facilities. Data disaggregated according to population/village, total morbidity/village, age, parasite species were collected by referring to the document in the district.

\section{Socio-demographic and socio-economic data collection}

This survey was conducted in 200 randomly selected households distributed over 12 study villages. There is a total of 8643 households in the study villages according to district census projection report 2015 and the number of households varied from village to village with least number of households (419) documented in Urji Oromia and the highest number (969) was in Ketta Bosoo village. Wayyu town (the capital of the district) was excluded from this survey as it outlies from the rest of the villages with its more urban setting. Thus, households included in the study sample were proportionally drawn from each village according to their number of households. The survey was conducted using a pretested structured questionnaire which was first developed in English and then the interviewer translated into the local language (Afaan Oromo) during the interview time as it was stated in the questionnaire. Each data collector was trained how to translate each question included in the questionnaire. The questionnaire contained the following categories of questions: demographic characteristics; questions related to malaria transmission, causation, signs, symptoms, burden, severity of the disease, treatment-seeking behavior, local prevention and control practices. The economic impact of malaria was calculated using open ended question. Thus, respondents were requested to estimate the frequency of the episode/ year, the family member get ill, the number of days lost, the amount of money spent per episode for transportation and for medical cost. All study participants were household heads with their age $\geq 18$ and gave their consent to be part of the study (Additional file 1).

\section{Data analysis}

Data was entered using SPSS version 20.00. The trend in mean malaria positivity rate reported from health facilities and mean adult mosquito population densities recorded during the study period were presented using line graphs. Chi-square test was used to determine proportional differences in respondents in relation to knowledge of malaria, malaria transmission mechanism and, control and prevention practices, before and after implementation of IVM interventions.

\section{Results}

\section{Socio-demographic characteristics}

In Table 1 the Socio-demographic status of Botor-Tolay community members or household heads who participated in the study was presented. There were more male-headed households than female headed households with the ratio being 4.83:1 in 2015 and 5.45:1 in 2018 . 
Table 1 Socio-demographic characteristics before and after implementation of IVM in Botor-Tolay district southwestern Ethiopia (2015-2018)

\begin{tabular}{|c|c|c|}
\hline Characteristics & Baseline (2015) & $\begin{array}{l}\text { After } \\
2018\end{array}$ \\
\hline Households sampled & 200 & 200 \\
\hline Gender of head of Household (male to female ratio) & 4.83 & 5.45 \\
\hline Mean family size & 4.22 & 5.55 \\
\hline Mean household head age & 37.5 & 38.96 \\
\hline \multicolumn{3}{|l|}{ Education n (\%) } \\
\hline Illiterate & $111(55.6)$ & $105(52.5)$ \\
\hline Primary school & $65(32.6)$ & $81(40.5)$ \\
\hline Secondary school & $21(10.7)$ & $10(5)$ \\
\hline Beyond secondary school & $3(1.5)$ & $4(2)$ \\
\hline \multicolumn{3}{|l|}{ Job description n(\%) } \\
\hline Farmer & $184(92)$ & $193(96.5)$ \\
\hline Gov. employee & $10(5)$ & $2(1)$ \\
\hline Private business & $6(3)$ & $5(2.5)$ \\
\hline \multicolumn{3}{|l|}{ Housing condition n(\%) } \\
\hline Brick \& cement wall, iron sheet cover & $1(0.5)$ & $3(1.5)$ \\
\hline mud plastered wall, iron sheet cover & $120(60)$ & $135(67.5)$ \\
\hline Mud plastered wall, thatched grass cover & $79(39.5)$ & $62(31)$ \\
\hline \multicolumn{3}{|l|}{ Livestock and human quarters are separate $\mathrm{n}(\%)$} \\
\hline Yes & $166(83)$ & $186(93)$ \\
\hline No & $34(17)$ & $14(7)$ \\
\hline \multicolumn{3}{|l|}{ Number of beds/sleeping spaces per family $n(\%)$} \\
\hline 1 & $118(59)$ & $53(26.5)$ \\
\hline 2 & $50(25)$ & $110(55)$ \\
\hline 3 and more & $32(16)$ & $37(18.5)$ \\
\hline
\end{tabular}

According to the respondents, each household had a mean family size of 4.2 persons in 2015 and 5.5 in 2018 . Roughly, half of the respondents $(55.6 \%$ in 2015 and $52 \%$ in 2018) were illiterate. $32.6 \%$ of the respondents had completed primary school in 2015 and with slight improvement, the proportion of primary school completeness reached $40.5 \%$ in 2018. Farming (small-scale persistent agriculture) remains the major means of livelihood, as the overwhelming majorities (92\% in 2015 and $96.5 \%$ in 2018) of the respondents were farmers. According to the respondents most of the community members (>97\%) lived in traditional houses (houses with mud plastered walls with iron sheet cover or with thatched grass cover). Most community members (83\% in 2015 and $93 \%$ in 2018) kept livestock in structures which were separate from human residences.

Household level awareness and knowledge about malaria transmission characteristics

Most of the respondents (85\% in 2015 and $90.5 \%$ in 2018 ) indicated that malaria is transmitted by mosquito bites which occur during the night (Table 2). The level of awareness among respondents to mosquito biting time showed significant increase $(p<0.001)$ in 2018 when compared to 2015. Similarly, respondents showed increased level of awareness in correctly identifying mosquito breeding habitats, typical malaria symptoms and mainstay vector control interventions (LLINs and IRS) in 2018; however, some aspects of behavioral changes in awareness lack significant increment when compared to the level of awareness measured in 2015. Respondents showed significant increase $(P<0.001)$ in the level of awareness in correctly identifying peak malaria season (from 37\% in 2015 to $83 \%$ in 2018), keeping the house walls without plastering for at least 6 months after spray (from $47 \%$ in 2015 to $82 \%$ in 2018) and knowing larval source management as a useful vector control tool (from $52.5 \%$ in 2015 to $88 \%$ in 2018). Discussing malaria related issues during family get together however, is not common among respondents as change in level of awareness still remains low (increased from $44.5 \%$ in 2015 to $49.5 \%$ in 2018 ). 
Table 2 Assessment of knowledge related to malaria transmission characteristics, before and after implementation of IVM in BotorTolay district southwestern Ethiopia (2015-2018)

\begin{tabular}{|c|c|c|c|c|}
\hline \multirow[t]{2}{*}{ Variables } & \multirow[t]{2}{*}{ Attributes } & \multicolumn{2}{|l|}{ Year } & \multirow{2}{*}{$\begin{array}{l}\mathrm{X}^{2} \text { - } \\
\text { square, } \\
p \text {-value }\end{array}$} \\
\hline & & $2015 \mathrm{n}(\%)$ & $2018 n(\%)$ & \\
\hline \multirow[t]{2}{*}{ understand mosquito bite as means of malaria transmission } & Yes & $170(85)$ & $181(90.5)$ & \multirow[t]{2}{*}{$P=0.093$} \\
\hline & No & $30(15)$ & $19(9.5)$ & \\
\hline \multirow[t]{2}{*}{ understand malaria vector mosquitoes biting time (night) } & Yes & $141(70.5)$ & $184(92)$ & \multirow[t]{2}{*}{$P<0.001$} \\
\hline & No & $59(29.5)$ & $16(8)$ & \\
\hline \multirow[t]{2}{*}{ Correctly identify potential mosquito breeding habitats (stagnant water) } & Yes & $161(80.5)$ & $170(85)$ & \multirow[t]{2}{*}{$P=0.234$} \\
\hline & No & $39(19.5)$ & $30(15)$ & \\
\hline \multirow[t]{2}{*}{ Correctly identify at least three malaria symptoms } & Yes & $148(74)$ & $154(77)$ & \multirow[t]{2}{*}{$P=0.485$} \\
\hline & No & $52(26)$ & $46(23)$ & \\
\hline \multirow[t]{2}{*}{ Identify mainstay malaria vector control interventions (IRS, LLINS) } & Yes & $142(71)$ & $150(75)$ & \multirow[t]{2}{*}{$P=0.368$} \\
\hline & No & $58(29)$ & $50(25)$ & \\
\hline \multirow[t]{2}{*}{ Malaria is treatable disease } & Yes & $180(90)$ & $178(89)$ & \multirow[t]{2}{*}{$P=0.744$} \\
\hline & No & $20(10)$ & $22(11)$ & \\
\hline \multirow[t]{2}{*}{ Correctly identify peak malaria season } & Yes & $74(37)$ & $166(83)$ & \multirow[t]{2}{*}{$P<0.001$} \\
\hline & No & $126(63)$ & $34(17)$ & \\
\hline \multirow[t]{2}{*}{ Know that walls should not be plastered for at least 6 months post-IRS } & Yes & $94(47)$ & $164(82)$ & \multirow[t]{2}{*}{$P<0.001$} \\
\hline & No & $106(53)$ & $36(18)$ & \\
\hline \multirow[t]{2}{*}{ Know that larval source management is useful vector control method } & Yes & $105(52.5)$ & $176(88)$ & \multirow[t]{2}{*}{$P<0.001$} \\
\hline & No & $95(47.5)$ & $24(12)$ & \\
\hline \multirow[t]{2}{*}{ Discuss malaria related issues during family get together } & Yes & $89(44.5)$ & 99 (49.5) & \multirow[t]{2}{*}{$P=0.316$} \\
\hline & No & $111(55.5)$ & $101(50.5)$ & \\
\hline
\end{tabular}

\section{Malaria testing and treatment seeking behavior}

Table 3 shows malaria testing, treatment seeking behavior and estimated loses in days and money due to the disease. Trend in malaria testing and treatment seeking behavior showed significant improvement $(P=0.004)$ in
2018 with proportion of respondents who sought malaria treatment increasing from $74 \%$ in 2015 to $85.5 \%$ in 2018. Concurrently, the reported interest to seek treatment in health facilities also showed significant change $(P<0.001)$ from $76 \%$ in 2015 to $90 \%$ in 2018 .

Table 3 Assessment of malaria treatment seeking behavior of the communities $(n=200)$ before and after implementation of IVM in Botor-Tolay district southwestern Ethiopia (2015-2018)

\begin{tabular}{|c|c|c|c|c|}
\hline \multirow[t]{2}{*}{ Variables } & \multirow[t]{2}{*}{ Attributes } & \multicolumn{2}{|l|}{ Year } & \multirow{2}{*}{$\begin{array}{l}X^{2}- \\
\text { square, } \\
p \text {-value }\end{array}$} \\
\hline & & 2015 & 2018 & \\
\hline \multirow[t]{2}{*}{ Person sought treatment } & Yes & $148(74)$ & $171(85.5)$ & \multirow[t]{2}{*}{$P=0.004$} \\
\hline & No & $52(26)$ & $29(14.5)$ & \\
\hline \multirow[t]{2}{*}{ Treatment sought from health facilities } & Yes & $152(76)$ & $180(90)$ & \multirow[t]{2}{*}{$P<0.001$} \\
\hline & No & $48(24)$ & $20(10)$ & \\
\hline \multirow[t]{2}{*}{ Treatment initiated within $24 \mathrm{~h}$ since the onset of first fever } & Yes & $70(35)$ & $85(42.5)$ & \multirow[t]{2}{*}{$P=0.124$} \\
\hline & No & $130(65)$ & $115(57.5)$ & \\
\hline \multirow[t]{2}{*}{ Treatment completed as per the prescription of health professional } & Yes & $171(85.5)$ & $174(87)$ & \multirow[t]{6}{*}{$P=0.663$} \\
\hline & No & $29(14.5)$ & $26(13)$ & \\
\hline Work days lost due to illness and caring/year & Mean \pm SE & - & $6.3 \pm 1.588$ & \\
\hline School days lost due to illness/year & Mean \pm SE & - & $2.30 \pm 0.16$ & \\
\hline Money lost per episode (medical) & Mean \pm SE & - & $13.3 \pm 6.04$ & \\
\hline Money lost per episode (transportation) & Mean \pm SE & - & $4.5 \pm 0.88$ & \\
\hline
\end{tabular}


Despite improved behavioral changes in seeking treatment from health facilities, the commitment among respondents to bring people with fever to health facilities within $24 \mathrm{~h}$ remained low, from $35 \%$ in 2015 to $42.5 \%$ in 2018. Economic data related to malaria episode (School days lost, money lost per episode for medical and transport) were not captured in 2015 and only the 2018 data was reported. Thus, an average of 6.3 working days were lost per person per year because either the parents became ill from malaria or due to time lost caring for a sick family member. Another mean 2.3 school days were lost per child per year due to malaria illness and families spent average 13.3 and 4.5 USD per episode for medical and transportation costs directly associated with malaria illness respectively.

Trend in malaria prevention practices in Botor-Tolay district (2015-2018)

Different malaria prevention interventions and assessment of community practices are presented in Table 4 . The trend in mosquito net ownership and universal coverage (i.e. one mosquito net for every two people) showed significant improvement in 2018 as compared to the coverage documented in 2015. The proportion of households owning at least one mosquito net increased from $83.5 \%$ in 2015 to $90 \%$ in 2018 and the proportion of households attained universal coverage increased from $56.5 \%$ in 2015 to $83 \%$ in 2018 . Moreover, the trend in prioritizing pregnant women and children under five when access to bed nets is limited significantly improved in 2018 (increased from $67.5 \%$ in 2015 to $89 \%$ in 2018). Despite the improved practices in ownership and coverage, people's commitment to use already available mosquito nets in their house remained low (40\% in 2015 and $49.5 \%$ in 2018). People's knowledge and practice in repairing damaged nets and washing them according to the WHO recommendation also remained very low. In contrary to improved net coverage documented in the area, proportion of house structures sprayed in $2018 \mathrm{sig}$ nificantly dropped (from $23.5 \%$ in 2015 to $10 \%$ in 2018). Trend in communities' participation in malaria education and larval source management showed significant improvement. Thus, the proportion of household heads participated in malaria education gatherings, community wide events increased from 33\% in 2015 to 55\% in 2018. Similarly, the proportion of households participating in larval source management increased from $26.5 \%$ in 2015 to $62 \%$ in 2018 .

\section{Malaria education, Larviciding and larval source management}

Community members and school communities received education through community wide events and meetings. People trained in implementation of IVM and

Table 4 Assessment of malaria prevention practices in communities $(n=200)$ before and after implementation of IVM in Botor-Tolay district southwestern Ethiopia (2015-2018)

\begin{tabular}{|c|c|c|c|c|}
\hline \multirow[t]{2}{*}{ Variables } & \multirow[t]{2}{*}{ Attributes } & \multicolumn{2}{|l|}{ Year } & \multirow{2}{*}{$\begin{array}{l}X^{2}- \\
\text { square, } \\
p \text {-value }\end{array}$} \\
\hline & & 2015 n (\%) & 2018 n (\%) & \\
\hline \multirow[t]{2}{*}{ Household has at least one mosquito net } & Yes & $167(83.5)$ & $180(90)$ & \multirow[t]{2}{*}{$P=0.055$} \\
\hline & No & $33(16.5)$ & $20(10)$ & \\
\hline \multirow[t]{2}{*}{ Household has at least one mosquito net for every two family members } & Yes & $113(56.5)$ & $166(83)$ & \multirow[t]{2}{*}{$P<0.001$} \\
\hline & No & $87(43.5)$ & $34(17)$ & \\
\hline \multirow[t]{2}{*}{ Family members slept under mosquito net in previous night } & Yes & $80(40)$ & $99(49.5)$ & \multirow[t]{2}{*}{$P=0.056$} \\
\hline & No & $120(60)$ & $101(50.5)$ & \\
\hline \multirow[t]{2}{*}{ Priority given to pregnant woman and children under five when access is limited } & Yes & $135(67.5)$ & $178(89)$ & \multirow[t]{2}{*}{$P<0.001$} \\
\hline & No & $65(32.5)$ & $22(11)$ & \\
\hline \multirow[t]{2}{*}{ Nets repaired when there is damage } & Yes & $45(22.5)$ & $51(25.5)$ & \multirow[t]{2}{*}{$P=0.482$} \\
\hline & No & $155(77.5)$ & $149(74.5)$ & \\
\hline \multirow[t]{2}{*}{ Mosquito nets washed as per WHO recommendation } & Yes & $25(12.5)$ & $38(19)$ & \multirow[t]{2}{*}{$P=0.074$} \\
\hline & No & $175(87.5)$ & $162(81)$ & \\
\hline \multirow[t]{2}{*}{ House sprayed in the last 12 months } & Yes & $47(23.5)$ & $20(10)$ & \multirow[t]{2}{*}{$P<0.001$} \\
\hline & No & $153(76.5)$ & $180(90)$ & \\
\hline \multirow[t]{2}{*}{ House hold head ever participated in malaria education } & Yes & $66(33)$ & $110(55)$ & \multirow[t]{2}{*}{$P<0.001$} \\
\hline & No & $134(67)$ & $90(45)$ & \\
\hline \multirow[t]{2}{*}{ Household head ever participated in larval source management } & Yes & $53(26.5)$ & $124(62)$ & \multirow[t]{2}{*}{$P<0.001$} \\
\hline & No & $147(73.5)$ & 76 (38) & \\
\hline
\end{tabular}


Table 5 Community members involved in malaria education, involved in larval source management and breeding habitat managed in Botor-Tolay district (2016-2018)

\begin{tabular}{|c|c|c|c|c|}
\hline \multirow{2}{*}{$\begin{array}{l}\text { Community members involved/habitats managed/ } \\
\text { Bti used }\end{array}$} & \multicolumn{3}{|l|}{ Year } & \multirow[t]{2}{*}{ Total } \\
\hline & 2016 & 2017 & 2018 & \\
\hline Community members received education & 6528 & 9325 & 6600 & 22,453 \\
\hline School communities received malaria education & 2473 & 4100 & 6226 & 12,799 \\
\hline Schools' anti-malaria clubs trained & 40/each & Re-enforced & Re-enforced & 480 \\
\hline Community working groups trained in each village & 4 & Re-enforced & Re-enforced & 48 \\
\hline Community members participated in LSM & 360 & 1325 & 488 & 2173 \\
\hline Military service people participated in LSM & 1151 & 1233 & 1202 & 3586 \\
\hline Health professional and policy makers trained & 28 & 28 & 28 & 84 \\
\hline Breeding habitat managed (hectare) & 36 & 34 & 30 & 100 \\
\hline Bti applied in breeding habitats (kg) & $18 \mathrm{~kg}$ & $17 \mathrm{~kg}$ & $15 \mathrm{~kg}$ & $50 \mathrm{~kg}$ \\
\hline
\end{tabular}

larval habitat management over a three-year period are presented in Table 5. In this process, more than 38,838 people (students, community members and military service men) received malaria education over three years through community wide events, coffee ceremony sessions and school-wide events. Six hundred twelve (612) people (community members, student representatives, health extension workers and policy makers) were trained in implementing IVM. In the process of involving communities in IVM, different activities including establishment of community based IVM working groups, creation of malaria-centered co-curricular activities in the schools, establishment of IVM learning centers and IVM demonstration sites were done. In an effort made to reduce potential mosquito breeding habitats, 100 ha of land was managed (drained, filled, and cleaned) through mobilization of community members, military service men and students. In addition, more than 1440 different habitats positive for mosquito larvae were treated with a total of $50 \mathrm{~kg} \mathrm{Bti}$ on bi-weekly bass for three years.

\section{Trend in adult Anopheles mosquito abundance}

Malaria vector population dynamics documented for four years is presented in Fig. 1. Over all 3445 anopheline and culicine mosquito were collected over four years period from 12 villages in Botor-Tolay using CDC light traps. Out of the total 3445 mosquitoes 1035 were An. gambiae s.l. and the rest 2410 were Culex mosquitoes. The highest total number of Anopheles mosquitoes (352) was collected in 2015 and the least (177) in 2018. There was no significant difference in mean mosquito density between 2015 and 2016 but significantly low mean mosquito density $(P<0.001)$ was collected in years $2017(0.44 /$ house/ trap-night) and 2018 (0.37/house/trap-night) as compared to the mean mosquito density collected in 2015 (0.73/house/trap-night).

\section{Trend in Anopheles mosquito larva abundance}

Monthly Anopheles mosquito larvae collection was made since July 2016 to December 2018 and presented in Fig. 2. Over all 11, 846 anopheline larvae were collected over two and half years sampling period from 12 villages in Botor-Tolay district using standard dipping method. Out of the total 11,846 Anopheline larvae, the highest number, 4734 (40\%) was collected in 2016 and the least number, 2555 (21.6\%) was collected in 2018.

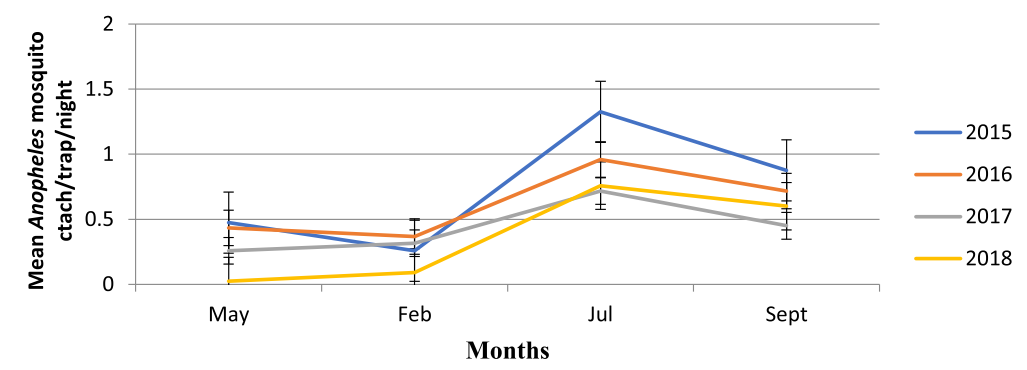

Fig. 1 Adult Anopheles population dynamics in the study area (2015-2018) 
Total

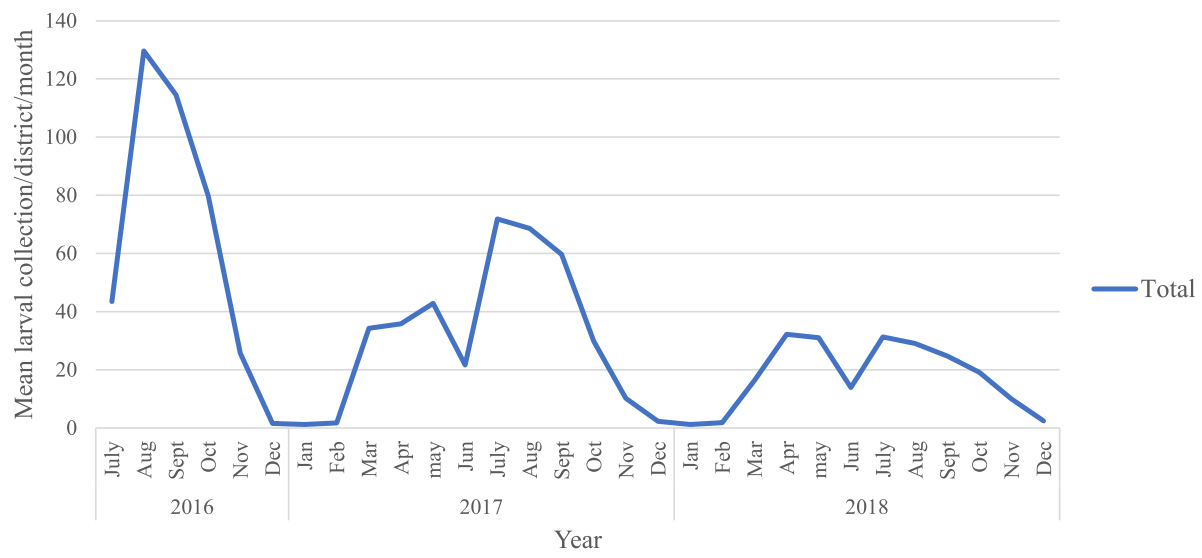

Fig. 2 Mean total Anopheles larvae collected from 12 study villages in Botor-Tolay district (2016-2018)

\section{Reported malaria cases in Tolay (2015-2018)}

Figure 3 shows trend of total malaria cases reported from health facilities found across 12 villages in BotorTolay. A total of 2065 malaria cases were documented over the four years from the health facilities (health centers, health posts) found in 12 study villages. The highest case report (1162) was documented in 2015 and the lowest case report (262) was documented in 2018. The rest 406 and 320 cases were recorded in 2016 and 2017 respectively. Malaria cases significantly declined $(P<$ 0.001) in 2016, 2017 and 2018 when compared to the base line data taken in 2015 however, further mean separation test showed that there was no statistically significant difference in mean malaria cases documented among years 2016, 2017 and 2018.

The percent of malaria cases reported from health facilities in comparison to all cause morbidity in Botor-Tolay between 2015 and 2018 were presented in Fig. 4. Thus, the share of malaria disease burden is the highest in 2015 accounting average $20.50 \%$ of all cause morbidity. Its burden share reduced to average
6.80, 6.34 and 4.65\% in 2016, 2017 and 2018, respectively.

\section{The relationship between monthly malaria cases and meteorological variables}

The relationship between climatic factors (Rainfall, maximum temperature, minimum temperature, relative humidity) and reported malaria cases in Botor-Tolay district was shown in Table 6. Accordingly, climatic factors relative humidity $(P<0.001)$, rainfall $(P=0.002)$ and minimum temperature $(P=0.003)$ had aggravative impact on malaria morbidity showing positive relationship whereas maximum temperature showed negative relationship. In addition, the monthly rainfall pattern and its impact on monthly malaria incidence between years 2015 and 2018 was presented in Fig. 5. Thus, major rainy season starts in July and continues until the beginning of September. Intermittent raining may continue until October but the subsequent months (November to February) remain mostly dry. Short rainy season starts towards the second half of March and continues to fall

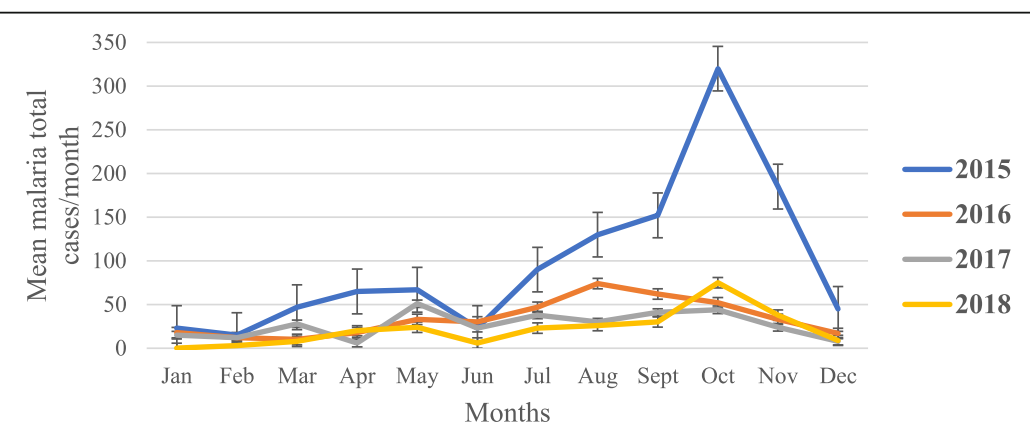

Fig. 3 The mean malaria total cases reported from health facilities from health facilities in Botor-Tolay district Southwestern Ethiopia (2015-2018) 


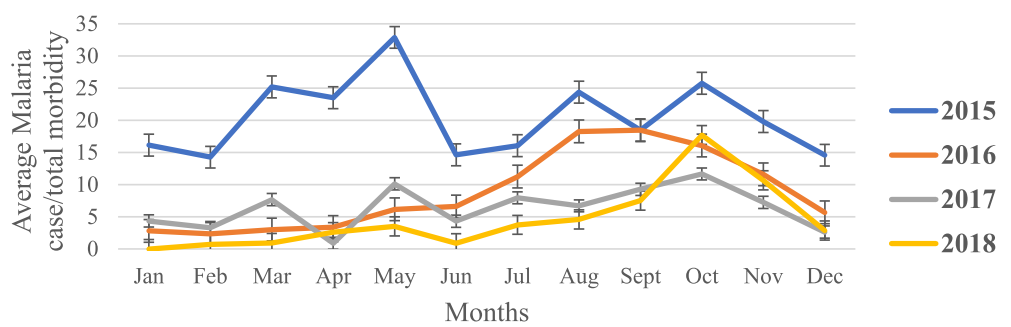

Fig. 4 The percent of malaria cases reported from health facilities in comparison to all cause morbidity in Botor-Tolay district Southwestern Ethiopia (2015-2018)

until the first half of May. The second half of May and June mostly remains dry. Malaria case build ups also follow up the rainfall pattern with slight lag. The total annual rainfall measurement for the district was found to be $1406.4 \mathrm{~mm}, 1471 \mathrm{~mm}, 1231.8 \mathrm{~mm}$ and $1185.1 \mathrm{~mm}$ in 2015, 2016, 2017 and 2018 respectively.

\section{Discussion}

In this study, the critical role played by the community in implementing integrated vector management for malaria control was investigated. In addition, the trend in behavioral change in community engagement in vector control activities, as well as their overall knowledge, attitude and practice towards malaria control and prevention was assessed. Year to year changes in the number of malaria cases at the local health centers and in the number of adult Anopheles mosquitoes collected indoors were used coarsely as the impact indicators of sustained community education and mobilization and implementation of actual mosquito control measures in the context of IVM. In this regard, an important limitation which warrants the results to be interpreted with caution was the fact that, due to ethical considerations, there were no non-intervention control villages where mosquito and malaria parameters could be measured in parallel for comparison purposes. It was also not feasible to implement a study design that could separately quantify the effects of CEM compared to those of the actual vector control methods, or from those of other confounding factors e.g., yearly variations in the occurrence and geographic extent of the potential mosquito breeding habitats due to variations in climatic variables such as rainfall.

Assessment of trends in people's knowledge before and after implementation of IVM in Botor-Tolay district towards malaria epidemiology including the mechanism of malaria transmission, time of mosquito bite, correctly identifying peak malaria season, correctly describing clinical manifestations of malaria, identifying potential mosquito breeding habitats showed significant improvement in 2018 as compared to the assessment made back in 2015. Despite, the lack of clear policy on IVM in
Ethiopia, elements of IVM such as community mobilization and education, malaria education using IEC/ BCC, through mass media such as radio and TV have been implemented by the NMCP since 2006 [19]. These concerted efforts by the NMCP to raise public awareness about malaria disease are reflected in increased awareness of the public according to community-based assessments made in recent years across the country (Amhara, Tigray, Gurage, Oromia, southern nations) which showed high improvement trend in people's knowledge on clinical symptoms [20, 21], mosquito bite as means of malaria transmission $[22,23]$ and stagnant water as mosquito breeding habitat [20]. In this study high level of knowledge about mainstay vector control interventions (LLINs and IRS), peak malaria season, how to safely handle IRS sprayed walls and knowing larval source management as useful vector control tool was documented. The improved knowledge level among community members clearly telling LLINs as major vector control intervention and right peak malaria season in this study were further supported by reports by Yimer et al. (2015) [22] from Abashege site and Yewhalaw et al. (2010) [24] from Asendabo area, southwestern Ethiopia. High level recognition of the role of IRS in malaria control in this study contrasted with the reports from both Yewhalaw et al. (2010) [24] and Aderaw and Gedefaw (2013) [25] whom documented very low awareness level up to 16.5 and $5.3 \%$ respectively.

In this study the trend in malaria testing and treatment seeking behavior showed significant improvement with $85.5 \%$ of the respondents seeking some form of treatment. Concurrently, the reported interest to seek treatment in health facilities also showed significant improvement with $90 \%$ of the respondents reporting that they brought people with any sign of disease to health facilities (government and private clinics). Generally, treatment seeking behavior for malaria diseases showed improvements across the country in recent reports [13; 24]. Higher treatment seeking behavior by community members was reported from Jimma Zone, southwestern Ethiopia by Yewhalaw et al. (2010) [24] with $71.5 \%$ and 33.8 of the respondents seeking treatment in public and private health facilities respectively. Higher treatment 
Table 6 The relationship between climatic variables and malaria morbidity in Botor-Tolay district (2016-2018)

\begin{tabular}{lll}
\hline Meteorological Variable & Correlation coefficient & $p$-value \\
\hline Mean Relative humidity & 0.728433 & $<0.001$ \\
Mean rainfall & 0.496976 & 0.002 \\
Mean Minimum temperature & 0.484132 & 0.003 \\
Mean Maximum temperature & -0.319760 & 0.057 \\
\hline
\end{tabular}

seeking behavior (82\%) was also recorded in nationwide study conducted in 2015 by Federal ministry of health in collaboration with Ethiopian public health institute [13]. Thus, improvements recorded in treatment seeking behavior in this study should be considered not only as a result of IVM interventions deployed but also partly because of the national malaria control programs put in place. Despite improved behavioral changes in seeking treatment from health facilities, the commitment among respondents to bring people with fever to health facilities within $24 \mathrm{~h}$ since the onset of clinical symptoms remains low. This is also a common challenge reported in nationwide studies conducted by federal ministry. According to malaria indicator survey conducted in 2007, 2011 and 2015 , only $15.5,51.3$ and $38.4 \%$ of respondents who had children with fever in two-week time prior to the interview had brought them to health facilities within 24 $h$ since the onset of fever respectively [13, 26, 27].

In this study it is shown that an average 6.3 working days were lost per year because either the parents get ill from malaria or due to caring members of the family. In addition to the working days, average 2.3 school days were lost per year due to malaria illness. Families spent average 13.3 and 4.5 USD per episode for medical and transportation costs directly associated with malaria illness. Studies conducted in Ethiopia estimating working or school days lost due to malaria illness are rare but a study conducted by icipe-impact assessment unit led by Minale Kassie (Kassie et al. 2015; unpublished) conducted in Tolay documented an average loss of 6.03 labor days in a fortnight, and incurred about average Birr 9.96 in malaria treatment during the same period. Another study conducted by Sicuri et al. (2013) [28] which analysed the economic costs of malaria in children under five years old in Ghana, Tanzania and Kenya confirmed the loss of approximately US\$ 5 per episode per child for non-complicated malaria in Tanzania and US\$ 288 per episode per child for cerebral malaria with neurological sequelae in Kenya.

Community engagement in vector control activities and disease control practices in Botor-Tolay district showed significant improvement in 2018 as compared to the coverage documented in 2015. Proportion of households owning at least one mosquito net increased to $90 \%$ and proportion of households reached universal coverage were $83 \%$. Pregnant woman and children under five were given priority when there is net scarcity. Increased community members involvement in malaria education and environmental management including draining, filling, and cleaning was also documented. Overall improvement in access to malaria and vector control practices were documented in study conducted in Abashege area, Guraege zone, south central Ethiopia (Yimer et al. 2015) [22] where access to at least one LLINs per household reached up to $98.7 \%$. This is a big stride towards ensuring universal coverage set by the NMCP and by far better than the $64 \%$ national average coverage of one LLIN per household according to the latest report from federal ministry [13]. Despite the improved practices in ownership and coverage, people's commitment to use already available mosquito nets in their houses, repairing damaged nets and washing them according to the WHO recommendation also remains very low. This could be attributed to relatively short period of education which we provided (three years only) as some behavioral changes may take longer time to be reflected. In this study, proportion of house structures sprayed in 2018 significantly dropped as compared to 2015. This could be due to government prioritization

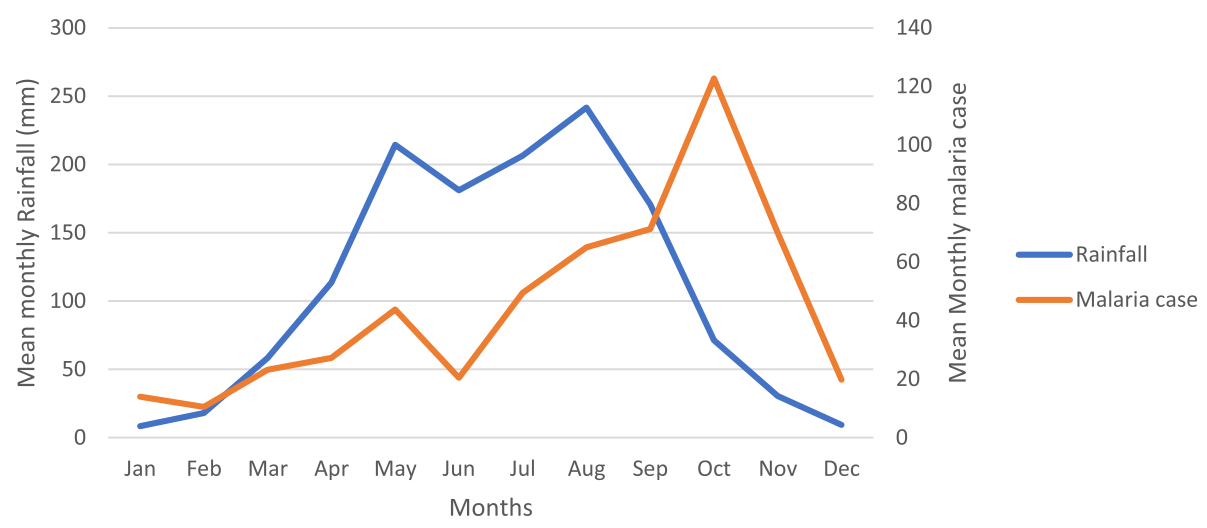

Fig. 5 Mean monthly rainfall pattern and corresponding malaria incidence in Botor-Tolay district, South western Ethiopia (2015-2018) 
of spray operation and channeling it to more transmission intense areas. Lack of compliance in proper use of the LLINs has proved to be a major problem throughout the country [13]. According to the study conducted by EPHI, only $40 \%$ of the respondents used the net in previous night. Low net maintenance rate $(3.7 \%)$ was documented in study conducted by Batisso et al., (2012) [29].

Community education and mobilization (CEM) in malaria control and prevention has been long stayed tradition in Ethiopia [10]. However, harmonizing it with other mainstay vector control interventions and mainstreaming it to policy level is a long overdue. In this study we showed the essence of CEM in curbing the disease burden through directly engaging community members (farmers, youth, school communities, military service men). In the process of involving communities in implementing IVM, different activities including establishment of community based IVM working groups, creation of malaria-centered co-curricular activities in the schools led by students, establishment of IVM learning centers and IVM demonstration sites were done. More than 100 ha of land was managed (drained, filled, and cleaned) in order to interrupt mosquito breeding. Different larva positive habitats were treated with $B t i$ on biweekly basis during larval peak season for three years. The increased engagement of communities in malaria control and prevention has led to dramatic decline in both the vector population and the disease burden. Yearly Mosquito density significantly declined in 2018 as compared to the density documented in 2015. Similarly, the measure of larvae population also showed significant decline between 2016 and 2018. As it is documented across different seasons, the vector population density dramatically declines in dry months (December, February and March) and starts to build in late March from which the population continues to grow until late May. There is brief decline in vector population between late May and June, but it starts to gain momentum again starting from July where it continues to peak until September. The rainfall pattern especially after a dry period affects how quickly a mosquito population builds up, hence the importance of when IRS is done and how effective larviciding can be. The temporal variation and seasonality of malaria vector population density in Ethiopia is well documented [30] and implementation of vector control measures were also designed in conformation with these variations [31]. We also examined the role of climatic factors, relative humidity, rainfall, minimum and maximum temperature of the area in relation to malaria morbidity. To this end the three climatic variables; relative humidity, rainfall and minimum temperature showed significant positive relationship with malaria morbidity likely contributing to the ongoing disease transmission. Temperature and rainfall are the key deriving climatic factors in malaria transmission in Ethiopia [32, 33]. The timing of indoor spray operations which is often conducted in August and September in Ethiopia would however be much effective if done taking in to account the dynamics of local climatic variables. This is because the onset, the intensity and the duration of the rainy season varies according to the local or reginal setting. This is evidenced for instance in Amhara region [34] where malaria burden stands higher in months of April and May following the onset of short rainy season which is in contrast to the reports from the rest of the country [35-37] where higher malaria burden is often documented in September and October. Moreover, spray operations are conducted once per year which is understandably due to the expensive nature of IRS intervention but there should be re-visit to cost benefit analysis made decades ago under different climatic and policy settings. Thus, targeted IRS operations conducted twice per year would not only curb the case build ups that we observe following the short and long rainy seasons but also it will significantly reduce the vector population which carries over the parasite to the next season.

Concurrently, malaria cases reported from health facilities also significantly declined across all the study villages. As we have described earlier; the documented reduction in cases in the study area were not solely attributed to the IVM activities introduced by this study group however increased engagement of communities through integrated vector management strategy has been found effective in significantly reducing malaria disease in Zambia [38], Tanzania [39] and Nigeria [40]. According to WHO position statement [41] Integrated vector management strategies including CEM, integration of both chemical and non-chemical methods, intra- and inter-sectoral collaboration, capacity building, evaluation of the whole process to make informed decision and supporting it with appropriate legislation not only helps us to achieve the envisaged goal with less expenditure but it is also an environmentally safe approach.

\section{Conclusion}

The introduction of IVM in Botor-Tolay district in Southwestern Ethiopia has led to significant decline in both malaria cases reported from health facilities and vector population documented during the study period. People's knowledge and practice of malaria prevention and control methods have significantly improved following the implementation of IVM in Botor-Tolay district, however the commitment among respondents to bring people with fever to health facilities within WHO recommended $24 \mathrm{~h}$ since the onset of clinical symptoms is very low. In addition, the practice of washing mosquito nets following WHO procedures and repairing them 
when there is damage is very low. In this study the incidence of malaria showed largely a bi-modal peak between March and May (the highest) and between September and November (the second peak) thus, spray operations would be much effective if done taking in to account the onset of these peaks preferably late march and late June/July.

\section{Supplementary information}

Supplementary information accompanies this paper at https://doi.org/10. 1186/s12889-019-7606-3.

Additional file 1. Cross sectional Survey Questionnaire.

\section{Abbreviations}

ACT: Artemisinin-based Combination Therapy; BCC: Behavioral Change Communication; Bti: Bacillus thuringiensis israelensis; CDC: Center for Disease Control and Prevention; CEM: Community Education and Mobilization; DDT: Dichlorodiphenyltrichloroethane; IEC: Information Education and Communication; IRS: Indoor Residual Spray; ITN: Insecticide Treated Net; IVM: Integrated Vector Management; LLINs: Long-lasting Insecticidal Nets; NMCP: National Malaria Control Program; WHO: World Health Organization

\section{Acknowledgements}

We thank Botor-Tolay district health officers and Tolay community health extension workers who involved in data collection. We would like to thank field entomological technicians Mr. Nejash Oli and Mr. Tiruneh Negassa whom tirelessly involved in larval source management and larviciding. This research was funded by Biovision Africa.

\section{Authors' contributions}

AA, CMM, CM and MG conceived and designed the study. AA analyzed the data and prepared the draft manuscript. DK involved in design of the work and coordinated data collection. All authors critically commented on the draft manuscript and approved the final draft.

\section{Funding}

This study was funded by Biovision Foundation. The funding organization had no role in designing, executing and interpreting the study.

\section{Availability of data and materials}

The datasets used and/or analysed during the current study are available from the corresponding author on reasonable request.

\section{Ethics approval and consent to participate}

The study protocol received ethical approval from the Kenya Medical Research Institute (KEMRI) Scientific and Ethics Review Unit (SERU) (SSC PROTOCOL No. 2675), as part of Integrated Vector Management (IVM) for Sustainable Malaria Control in Eastern Africa (Ref. KEMRI/Res/7/3/1). Additional consent was obtained by support letter from Tolay District Health Bureau. written informed consent was obtained from all participants.

\section{Consent for publication}

Not applicable.

\section{Competing interests}

All the authors declare that they have no competing interest.

\section{Author details}

IInternational Center of Insect Physiology and Ecology, Addis Ababa, Ethiopia. ${ }^{2}$ College of Natural Sciences, Addis Ababa University, Addis Ababa, Ethiopia. ${ }^{3}$ Kenya Medical Research Institute - Wellcome Trust Research Programme, Nairobi, Kenya. International Center of Insect Physiology and Ecology, Nairobi, Kenya. ${ }^{5}$ School of Health Systems and Public Health, University of Pretoria Institute for Sustainable Malaria Control, University of Pretoria, Pretoria, South Africa.
Received: 24 April 2019 Accepted: 9 September 2019

Published online: 21 October 2019

\section{References}

1. WHO. World Health Organization, \& UNICEF. Global vector control response 2017-2030; 2017.

2. WHO. World malaria report. Geneva: World Health Organization; 2017. Licence: CC BY-NC-SA 3.0 IGO; 2017b

3. WHO. Global technical strategy for malaria 2016-2030. Geneva: World Health Organization; 2015.

4. WHO. Implementation of the global malaria control strategy: report of a WHO Study Group on the Implementation of the Global Plan of Action for Malaria Control 1993-2000 [meeting held in Geneva from 8 to 12 February 1993]; 1993.

5. WHO. Global strategic framework for integrated vector management. No. WHO/CDS/CPE/PVC/2004.10. Geneva: World Health Organization; 2004.

6. Beier JC, Joseph K, John IG, Michael BM, Daniel El, Robert JN. Integrated vector management for malaria control. Malar J. 2008;7(1):S4.

7. Vanlerberghe V, Toledo ME, Rodriguez M, Gomez D, Baly A, Benitez JR, Van Der Stuyft P. Community involvement in dengue vector control: cluster randomized trial. Bmj. 2009;338:b1959.

8. Andersson N, Nava-Aguilera E, Arosteguí J, Morales-Perez A, Suazo-Laguna $\mathrm{H}$, Legorreta-Soberanis J, et al. Evidence based community mobilization for dengue prevention in Nicaragua and Mexico (Camino Verde, the green way): cluster randomized controlled trial. Bmj. 2015;351:h3267.

9. Mitchell-Foster K, Ayala EB, Breilh J, Spiegel J, Wilches AA, Leon TO, et al. Integrating participatory community mobilization processes to improve dengue prevention: an eco-bio-social scaling up of local success in Machala, Ecuador. Trans R Soc Trop Med Hyg. 2015;109(2):126-33.

10. Ghebreyesus TA, Alemayehu T, Bosma A, Witten KH, Teklehaimanot A. Community participation in malaria control in Tigray region Ethiopia. Acta Trop. 1996;61(2):145-56.

11. Ingabire CM, Alaii J, Hakizimana E, Kateera F, Muhimuzi D, Nieuwold I, et al. Community mobilization for malaria elimination: application of an open space methodology in Ruhuha sector, Rwanda. Malar J. 2014;13(1):167.

12. Chaki PP, Kannady K, Mtasiwa D, Tanner M, Mshinda H, Kelly AH, et al. Institutional evolution of a community-based program for malaria control through larval source management in Dar Es Salaam, United Republic of Tanzania. Malar J. 2014;13(1):245.

13. Ethiopian Public Health Institute (EPHI). Ethiopia National Malaria Indicator Survey 2015. In: Ethiopian Public Health Institute Addis Ababa Ethiopia; 2016.

14. PMI. PRESIDENT'S MALARIA INITIATIVE ETHIOPIA Malaria Operational Plan FY 2018. Online available: https:/www.pmi.gov/docs/default-source/defaultdocument-library/malaria-operational-plans/fy-2018/fy-2018-ethiopiamalaria-operational-plan.pdf.

15. Valent BioSciences. VectoBac ${ }^{\oplus}$ WG bacterial larvicide: technical use sheet. Valent BioSciences 2003. Online available at: https://www.valentbiosciences. com/publichealth/wp-content/uploads/sites/4/2017/02/vectobac-wdgtechnical-use-sheet.pdf

16. World Health Organization. Malaria entomology and vector control. 2013.

17. Gillies MT, De Meillon B. The anopheline of Africa south of the Sahara (Ethiopian zoogeographical region). The Anophelines of Africa south of the Sahara (Ethiopian Zoogeographical Region); 1968.

18. Gillies MT, Coetzee M. A supplement to the Anophelinae of Africa south of the Sahara. Johannesburg: Publications of the South African Institute of Medical Research; 1987. p. 55.

19. Federal Ministry of Health (FMoH). National Five-Year Strategic Plan for Malaria Prevention \& Control In Ethiopia 2006 - 2010. 2016

20. Deressa W, Ali A, Enquoselassie F. Knowledge, attitude and practice about malaria, the mosquito and antimalarial drugs in a rural community. EJHD. 2003;17(2):99-104.

21. Paulander J, Olsson H, Lemma H, Getachew A, San Sebastian M. Knowledge, attitudes and practice about malaria in rural Tigray, Ethiopia. Glob Health Action. 2009;2(1):1839.

22. Yimer F, Animut A, Erko B, Mamo H. Past five-year trend, current prevalence and household knowledge, attitude and practice of malaria in Abeshge, south-Central Ethiopia. Malar J. 2015;14(1):230.

23. Abate A, Degarege A, Erko B. Community knowledge, attitude and practice about malaria in a low endemic setting of Shewa Robit town, northeastern Ethiopia. BMC Public Health. 2013;13(1):312. 
24. Yewhalaw D, Kassahun W, Woldemichael K, Tushune K, Sudaker M, Kaba D, et al. The influence of the Gilgel-gibe hydroelectric dam in Ethiopia on caregivers' knowledge, perceptions and health-seeking behavior towards childhood malaria. Malar J. 2010:9(1):47.

25. Aderaw Z, Gedefaw M. Knowledge, attitude, and practice of the community towards malaria prevention and control options in anti-malaria association intervention zones of Amhara national regional state, Ethiopia. Glob J Med Res. 2013. https://medicalresearchjournal.org/index.php/GJMR/article/ view/457.

26. Federal Ministry of Health (FMoH). Ethiopia National Malaria Indicator Survey 2007. Addis Ababa: Federal Democratic Republic of Ethiopia Ministry of Health; 2008.

27. Ethiopian Public Health Institute (EPHI). Ethiopia National Malaria Indicator Survey 2011. Addis Ababa: The Ethiopian Health and Nutrition Research Institute \& partners; 2102

28. Sicuri E, Vieta A, Lindner L, Constenla D, Sauboin C. The economic costs of malaria in children in three sub-Saharan countries: Ghana, Tanzania and Kenya. Malar J. 2013;12(1):307.

29. Batisso E, Habte T, Tesfaye G, Getachew D, Tekalegne A, Kilian A. A stitch in time: a cross-sectional survey looking at long lasting insecticide-treated bed net ownership, utilization and attrition in SNNPR, Ethiopia. Malar J. 2012;11(1):183

30. McCann JC. The historical ecology of malaria in Ethiopia. Deposing the spirits. Athens: Ohio University Press; 2014.

31. Ministry of Health. National strategic plan for malaria prevention, control and elimination in Ethiopia, 2011-2015. Addis Ababa: Ministry of Health of Ethiopia; 2010. http://www.nationalplanningcycles.org/sites/default/files/ country_docs/Ethiopia/ethiopia_malaria_national_strategic_plan_2011-2 015_130810.pdf. Accessed 29 July 2019.

32. FMoH. National five-year strategic plan for malaria control in Ethiopia: 20012005. Malaria and other vector-borne diseases prevention and control team, diseases prevention and control department. Addis Abba: Federal Ministry of Health, Federal Democratic Republic of Ethiopia; 2001.

33. Fontaine RE, Najjar AE, Prince JS. The 1958 malaria epidemic in Ethiopia. Am J Trop Med Hyg. 1961;10:795-803.

34. Tewabe T. Malaria Situation in Amhara Regional State. In: Workshop on Integrated Vector Management for Malaria Control in Ethiopia. Gurd Shola, ILRI Campus. Addis Ababa: ICIPE-Ethiopia; 2018. p. 10-5.

35. Alemu A, Abebe G, Tsegaye W, Golassa L. Climatic variables and malaria transmission dynamics in Jimma town, south West Ethiopia. Parasites vectors. 2011;4(1):30

36. Woyessa A, Deressa W, Ali A, Lindtjørn B. Prevalence of malaria infection in Butajira area, south-Central Ethiopia. Malar J. 2012;11(1):84.

37. Taffese HS, Hemming-Schroeder E, Koepfli C, Tesfaye G, Lee MC, Kazura J, et al. Malaria epidemiology and interventions in Ethiopia from 2001 to 2016. Infect Dis Poverty. 2018;7(1):103.

38. Chanda E, Masaninga F, Coleman M, Sikaala C, Katebe C, MacDonald M. Integrated vector management: the Zambian experience. Malar J. 2008;7(1):164.

39. Bang YH, Sabuni IB, Tonn RJ. Integrated control of urban mosquitoes in Dar Es Salaam using community sanitation supplemented by larviciding. EAMJ. 1975:52:578-88

40. Gilroy AB, Bruce-Chwatt LJ. Mosquito-control by swamp drainage in the coastal belt of Nigeria. Ann Trop Med Parasitol. 1945;39:19-40.

41. World Health Organization (WHO). WHO position statement on integrated vector management. Weekly Epidemiological Record= Relevé épidémiologique hebdomadaire. 2008:83(20):177-81.

\section{Publisher's Note}

Springer Nature remains neutral with regard to jurisdictional claims in published maps and institutional affiliations.

Ready to submit your research? Choose BMC and benefit from:

- fast, convenient online submission

- thorough peer review by experienced researchers in your field

- rapid publication on acceptance

- support for research data, including large and complex data types

- gold Open Access which fosters wider collaboration and increased citations

- maximum visibility for your research: over $100 \mathrm{M}$ website views per year

At BMC, research is always in progress.

Learn more biomedcentral.com/submissions 